\section{Drs. Lambert and Maksymowych reply}

\section{To the Editor:}

We read with interest the letter in this issue by Hall-Craggs and colleagues ${ }^{1}$ discussing the developing field of diffusion-weighted imaging (DWI) and its application for quantification of inflammation in rheumatology. As proponents of quantification in medical imaging, we agree that DWI does indeed have some advantages. Its ability to objectively quantify diffusivity of water molecules in the brain was well established many years $\mathrm{ago}^{2}$ and is now absolutely essential for magnetic resonance imaging (MRI) of stroke, providing unique information about brain cell injury due to hypoxia. DWI is now often used for detection and characterization of tumors ${ }^{3}$. However, its application for assessment of inflammation outside the brain is at an earlier stage of development. One potentially exciting application may be the assessment of synovitis, where conventional sequences have difficulty distinguishing inflamed synovium from effusion without intravenous (IV) injection of a contrast agent. If DWI turns out to be a suitable substitute for the IV injection ${ }^{4}$, it would be a significant advance, especially for children.

It has been shown by Vendhan, et al that DWI measurements of sacroiliitis correlate closely with observed quantification of bone marrow edema on short-tau inversion recovery sequences $(R=0.85)^{5}$. In this publication, the measurement of apparent diffusion coefficient (ADC) required an observer to place regions of interest (ROI) on DWI images. A second observer was told how many ROI to place and on which images to place them, but not exactly where to place them. The resulting interobserver agreement for the normalized ADC measurements was 0.64. This may be satisfactory but it is not impressive for a measurement that Hall-Craggs, et $a l^{1}$ emphasize is objective. Of course things improve with experience, and 2 years later the same author group had intraclass correlation coefficient for DWI of the sacroiliac (SI) joints in the range of 0.81-0.98, using different methodology ${ }^{6}$. Recently, Bradbury, et $a l^{7}$ confirmed that DWI corresponds closely with observer quantification of bone marrow edema (BME). Their conclusion that "DWI has excellent performance as a diagnostic tool in distinguishing axSpA [axial spondyloarthritis] from noninflammatory causes of back pain" may be true but not based on their own data, because their study design required subjects in the control group to not meet the Assessment of Spondyloarthritis international Society (ASAS) imaging criteria. In addition, the mean Spondyloarthritis Research Consortium of Canada SI joint score for this group was 0 . In other words, their control group did not represent a typical low back pain population, which frequently demonstrates small foci of BME in the SI joints ${ }^{8,9,10}$. More recently, it was shown that DWI may improve the specificity of a diagnostic MRI scan without significantly changing its overall diagnostic performance ${ }^{11}$. In this publication, the area under the curve for diagnostic ascertainment using measured ADC values was inferior to subjective assessment of the MRI, although the difference was not significant. This is not surprising, because regardless of whether quantification of BME is helpful for diagnostic purposes, it does not incorporate information arising from localization of BME and the contextual interpretation with other imaging findings that contribute enormously to diagnosis such as erosion. It is problematic that many reports refer to a "positive" MRI, as defined by the ASAS criterion, as now being "an important component of diagnostic pathways in spondyloarthritis ${ }^{12}$." This criterion, which is based solely on the assessment of BME, was generated by consensus for the purposes of classifying patients with axSpA and was never intended to be adopted for diagnostic purposes.

A whole range of new MRI mapping techniques are now available permitting quantification such as $\mathrm{T} 1, \mathrm{~T} 1 \mathrm{\varrho}, \mathrm{T} 2$, and $\mathrm{T} 2 *$ mapping as well as DWI and chemical-shift encoded MRI. It seems likely that some form of quantification will become a significant part of many future applications of MRI. In the meantime, it should be emphasized that nearly all these MRI techniques still rely in part on medical imaging and expert interpretation of both the imaging and numerical results. MRI "maps" are in fact "images" within which the varying color/brightness of the pixels represent a particular property of the tissue. An ADC map (image) is objectively created but still requires interpretation, and when an observer places a region of interest over an area of the map, the results may be subject to significant observer variation ${ }^{11}$. It is hoped that artificial intelligence and computer-aided detection will have a major role in assisting the human observer to better interpret MRI results in the future, thus easing the load for the observers and enhancing patient care and clinical trial research. While objectivity is preferable to subjectivity, objectivity alone does not confer usefulness. There are pathophysiological reasons why the application of DWI for diagnostic ascertainment of bone marrow inflammation in rheumatology may have limited clinical utility, and its future use is likely to primarily focus on clinical trial research.

ROBERT G. LAMBERT (), MBBCh, FRCPC, Professor of Radiology, University of Alberta and Staff Radiologist, University of Alberta Hospital; WALTER P. MAKSYMOWYCH 1 , MBBS, FRCPC, Professor of Rheumatology, University of Alberta and Staff Rheumatologist, University of Alberta Hospital, Edmonton, Alberta, Canada. Address correspondence to Prof. R.G. Lambert, Department of Radiology and Diagnostic Imaging, University of Alberta, 2A2.WMC, 8440-112 St., Edmonton, Alberta T6G 2B7, Canada. E-mail: rlambert@ualberta.ca

\section{REFERENCES}

1. Hall-Craggs MA, Bray TJ, Ciurtin C, Bainbridge A. Quantitative magnetic resonance imaging has potential for assessment of spondyloarthritis: arguments for its study and use. J Rheumatol 2019;46:541-2.

2. Rowley HA, Grant PE, Roberts TP. Diffusion MR imaging. Theory and applications. Neuroimaging Clin N Am 1999;9:343-61.

3. Taouli B, Beer AJ, Chenevert T, Collins D, Lehman C, Matos C, et al. Diffusion-weighted imaging outside the brain: consensus statement from an ISMRM-sponsored workshop. J Magn Reson Imaging 2016;44:521-40.

4. Barendregt AM, van Gulik EC, Lavini C, Nusman CM, van den Berg JM, Schonenberg-Meinema D, et al. Diffusion-weighted imaging for assessment of synovial inflammation in juvenile idiopathic arthritis: a promising imaging biomarker as an alternative to gadolinium-based contrast agents. Eur Radiol 2017;27:4889-99.

5. Vendhan K, Bray TJ, Atkinson D, Punwani S, Fisher C, Sen D, et al. A diffusion-based quantification technique for assessment of sacroiliitis in adolescents with enthesitis-related arthritis. $\mathrm{Br} \mathrm{J}$ Radiol 2016;89:20150775.

6. J P Bray T, Vendhan K, Ambrose N, Atkinson D, Punwani S, Fisher $\mathrm{C}$, et al. Diffusion-weighted imaging is a sensitive biomarker of response to biologic therapy in enthesitis-related arthritis. Rheumatology 2017;56:399-407.

7. Bradbury LA, Hollis KA, Gautier B, Shankaranarayanan S, Robinson PC, Saad N, et al. Diffusion-weighted imaging is a sensitive and specific magnetic resonance sequence in the diagnosis of ankylosing spondylitis. J Rheumatol 2018;45:771-8.

8. Weber U, Lambert RG, Ostergaard M, Hodler J, Pedersen SJ, Maksymowych WP. The diagnostic utility of magnetic resonance imaging in spondylarthritis: an international multicenter evaluation of one hundred eighty-seven subjects. Arthritis Rheum 2010;62:3048-58.

9. Aydin SZ, Maksymowych WP, Bennett AN, McGonagle D, Emery $\mathrm{P}$, Marzo-Ortega $\mathrm{H}$. Validation of the ASAS criteria and definition of a positive MRI of the sacroiliac joint in an inception cohort of axial spondyloarthritis followed up for 8 years. Ann Rheum Dis 2012;71:56-60.

10. Weber U, Ostergaard M, Lambert RG, Pedersen SJ, Chan SM, Zubler V, et al. Candidate lesion-based criteria for defining a positive sacroiliac joint MRI in two cohorts of patients with axial spondyloarthritis. Ann Rheum Dis 2015;74:1976-82.

11. Beltran LS, Samim M, Gyftopoulos S, Bruno MT, Petchprapa CN. Does the addition of DWI to fluid-sensitive conventional MRI of the sacroiliac joints improve the diagnosis of sacroiliitis? Am J Roentgenol 2018;210:1309-16.

12. Hall-Craggs MA, Bray TPJ, Bainbridge AP. Quantitative imaging of inflammatory disease: are we missing a trick? Ann Rheum Dis 2018;77:1689-91.

J Rheumatol 2019;46:5; doi:10.3899/jrheum.181215 